\title{
The shape of the Lego brick is free for all to use
}

Patricia Cappuyns*

The famous Lego construction brick is a shape with a technical function. It enjoyed patent protection under the original 'Kiddicraft' patents and additional protection under the amended patents filed by Lego. Ever since its patents expired, Lego has sought to carve out the shape of the Lego brick from the public domain and reclaim its monopoly by asserting other types of IP rights, including copyrights, design rights, and most recently trade marks.

In light of the public interests underlying the functionality exclusion in Article 7(1)(e)(ii) of the Community Trade Mark Regulation (CTMR), ${ }^{1}$ the Office for the Harmonisation of the Internal Market (OHIM) has not allowed Lego's attempt to re-monopolize its formerly patented technical invention under the guise of trade mark law. Both the Cancellation Division and the Grand Board of Appeal held that the registration of the 3D trade mark awarded by the Examiner should be cancelled in application of the functionality exclusion. This cancellation has now been confirmed by the European Court of First Instance (CFI) in a judgment of 12 November 2008.

In this article, I explain the factual background of Lego $v$ OHIM-MEGA Brands and its procedural history, the functionality exclusion and its application by the European Court of Justice in Philips $v$ Remington, with particular attention to the policy interests underlying this exclusion and finally the CFI's application of the teachings of Philips $v$ Remington in its judgment of 12 November 2008.

\section{The construction brick, the Page/Lego patents, and the CTM under review}

On 1 April 1996, Lego filed Community trade mark No. 107029 for various goods in class 9, as well as for 'games and playthings; gymnastic and sporting articles (included in class 28); decorations for Christmas trees'

* The author is a partner with Howrey LLP in Brussels and represents MEGA Brands in the proceedings against Lego, together with her colleague Carl De Meyer. She is grateful to Carl for his comments on this article. Email: patricia.cappuyns@howrey.com

\section{Key issues}

- In this article, the author seeks to establish what is the right balance between patent and trade mark rights.

- The article also explores issues surrounding what makes a shape functional and whether a functional shape can be protected as a trade mark.

- Finally, the author asks whether the existence of alternative shapes matters in the context of the functionality exclusion.

in class 28. The colour 'red' was claimed in the description. The mark was filed as a three-dimensional mark, and consisted of a toy construction brick, represented as follows:

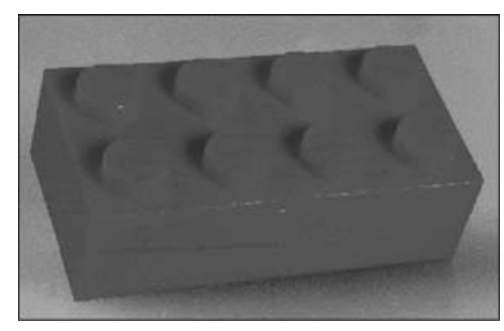

The brick represented in the CTM is not a Lego invention. The basic stackable interlocking toy brick that is the corner stone of the Lego modular toy system was invented by Hilary 'Harry' Fisher Page in the 1930s. The bricks invented by Page were first marketed by Kiddicraft Ltd. in the UK, France, and other countries as 'Kiddicraft Self Locking Building Bricks'.
1 Council Regulation (EC) 40/94 of 20 December 1993 on the Community Trade Mark, now codified as Council Regulation (EC) 207/2009 of 26 February 2009 on the Community Trade Mark (hereafter 'CTMR'). The numbering of Art 7 (1)(e)(ii) remains unchanged. 
Page was granted several patents in the UK and elsewhere, including France and Canada. The figures in UK patent No. 587,206 show that the invention is characterized by the presence of cylindrical connecting knobs on the upper side of the block, usually referred to as 'primary projections'.

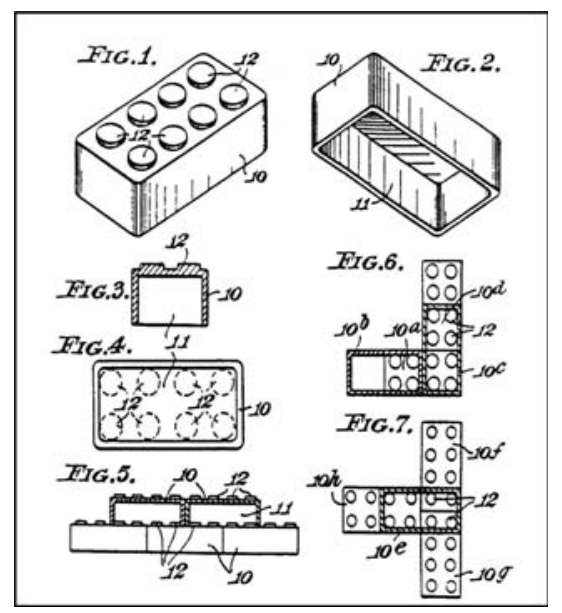

The shape of the CTM at issue is essentially identical to the shape of Mr Page's brick shown in Fig. 1 of UK Patent No. 587,206.

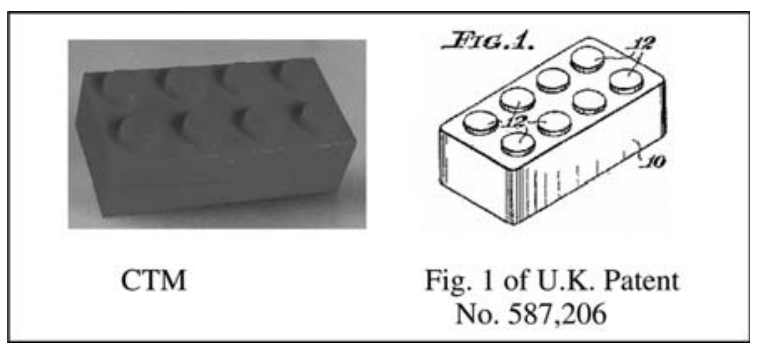

The 'Kiddicraft' brick served as the basis for Lego's own bricks. After acquiring the Page patents in the late 1940s and commercializing 'Kiddicraft'inspired bricks for several years, Lego made a further improvement in 1958. In Lego's improved brick, Mr Page's array of primary connecting knobs remained unchanged on the top surface of the brick. However, secondary projections or 'tubes' were introduced to enhance the functionality of the primary projections by adding more engagement points. Also of a cylindrical shape, the tubes provided for greater rigidity and stability, sometimes described as 'clutch power', and additional possibilities to combine the bricks.

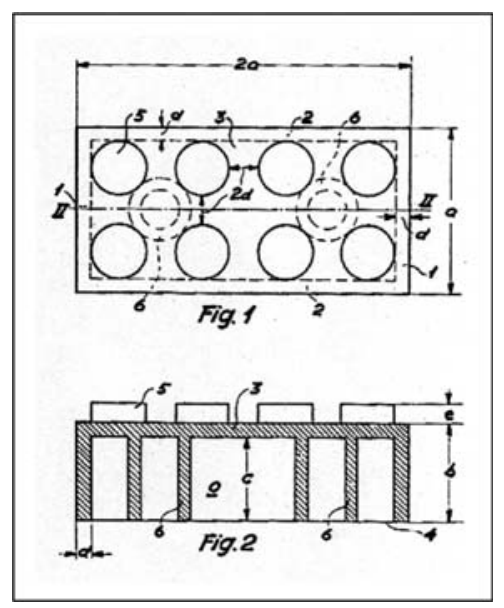

It is noteworthy that the only shape described, illustrated, and claimed in Lego's patent for the primary projections (connecting knobs) is cylindrical. In contrast, various alternative shapes were disclosed for the secondary projections:

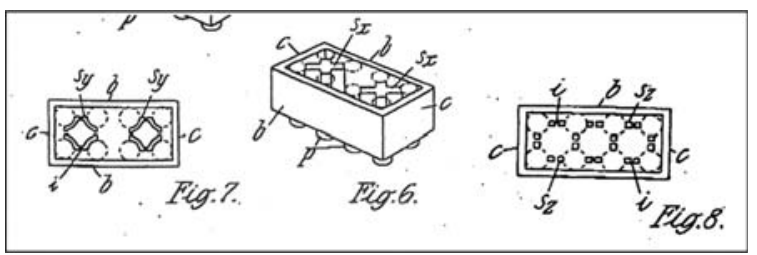

When identifying the preferred embodiment of the improved building blocks, Lego specifically stated that 'in a preferred embodiment, both the primary and the secondary projections are of cylindrical shape...'?

By the early 1990s, the pioneering Page patents and Lego's improvement patents had all expired. Consequently, the technical features described and claimed in these expired patents should be freely available for use by anyone who wishes to compete in the market for construction toys.

However, following the expiry of its patents Lego sought to carve out the shape of the LEGO brick from the public domain and reclaim its monopoly by asserting other types of IP rights, including copyrights, design rights, and trade marks. The CTM that Lego applied for in 1996 covered a toy brick with exactly the same shape as Lego's expired improvement patents. 
If granted, this CTM would allow Lego to prevent competitors from using the best, most functional shape available for toy construction bricks described in those patents, thereby severely limiting if not excluding all effective competition and enjoying a monopoly that would potentially be perpetual.

\section{Procedural history of Lego v OHIM- MEGA Brands}

Although the CTM was initially granted, in a decision of 30 July 2004, it was declared invalid by the OHIM Cancellation Division for 'construction toys' in class 28 on the basis of Article 7(1)(e)(ii) CTMR. ${ }^{3}$ In its first ever decision, the OHIM Grand Board rejected Lego's appeal and confirmed the cancellation of the registration on 10 July $2006 .{ }^{4}$ On 12 November 2008, the European CFI dismissed Lego's appeal against the decision of the OHIM Grand Board and again confirmed the cancellation of the registration. ${ }^{5}$ An appeal is still pending before the European Court of Justice.

\section{The availability of trade mark protection for functional shapes in Europe: Article 7(1)(e)(ii) CTMR and Philips v Remington}

\author{
Article 7(1)(e)(ii) states: ${ }^{6}$
}

The following shall not be registered: (...)

(e) signs which consist exclusively of: (...)

(ii) the shape of goods which is necessary to obtain a technical result;

The seminal case on the availability of trade mark protection for functional shapes is the Philips $v$ Remington judgment of the European Court of Justice concerning the well-known three-headed Philips shaver. ${ }^{7}$ Interpreting Article 3 of the Trade Mark Directive-which corresponds to Article 7 CTMR - in light of the underlying public interest, the ECJ held that the purpose of Article 3(1)(e) is to prevent trade mark protection from creating a monopoly on technical solutions or the functional characteristics of a product:

3 OHIM Cancellation Division, 30 July 2004, OHIM reference no. 63 C 107029/1.

4 OHIM Grand Board of Appeal, 10 July 2006, case R 856/2004-G.

5 CFI, 12 November 2008, Case T-270/06 Lego Juris A/S v OHIM-MEGA Brands, Inc (hereafter 'Lego v OHIM-MEGA Brands').

6 The corresponding provision of the First Directive 89/104/EEC of the Council of 21 December 1988 to approximate the laws of the Members States relating to trade marks was Art 3(1)(e) second indent. It is now
The rationale of the grounds for refusal of registration laid down in Article 3(1)(e) of the Directive is to prevent trade mark protection from granting its proprietor a monopoly on technical solutions or functional characteristics of a product which a user is likely to seek in the products of competitors. Article 3(1)(e) is thus intended to prevent the protection conferred by the trade mark right from being extended, beyond signs which serve to distinguish a product or service from those offered by competitors, so as to form an obstacle preventing competitors from freely offering for sale products incorporating such technical solutions or functional characteristics in competition with the proprietor of the trade mark. ${ }^{8}$

Individuals should not be allowed to acquire or perpetuate exclusive trade mark rights relating to technical solutions, and competitors should not be limited by such exclusive trade mark rights in their freedom of choice between shapes whose essential characteristics perform a technical function.

As regards, in particular, signs consisting exclusively of the shape of the product necessary to obtain a technical result, listed in Article 3(1)(e), second indent, of the Directive, that provision is intended to preclude the registration of shapes whose essential characteristics perform a technical function, with the result that the exclusivity inherent in the trade mark right would limit the possibility of competitors supplying a product incorporating such a function or at least limit their freedom of choice in regard to the technical solution they wish to adopt in order to incorporate such a function in their product.

As Article 3(1)(e) of the Directive pursues an aim which is in the public interest, namely that $a$ shape whose essential characteristics perform a technical function and were chosen to fulfil that function may be freely used by all, that provision prevents such signs and indications from being reserved to one undertaking alone because they have been registered as trade marks (see, to that effect, Windsurfing Chiemsee, paragraph 25). ${ }^{9}$

The fact that other shapes exist which could achieve the same technical result cannot overcome the ground for invalidity contained in Article 3(1)(e)(ii) of the Directive. The existence of other shapes is irrelevant to the question of whether the shape under consideration is necessary to obtain a technical result:

Art 3(1)(e)(ii) of Directive 2008/95 of 22 October 2008 to approximate the laws of the Member States relating to trade marks (hereafter the 'Trade Mark Directive').

7 Koninklijke Philips v Remington Case C-299/99 [2002] ECR I-5475, [2002] ETMR 81 (hereafter 'Philips $v$ Remington').

8 Philips $v$ Remington, paragraph 78, emphasis added.

9 ibid, paragraphs 79-80, emphasis added. 
As to the question whether the establishment that there are other shapes which could achieve the same technical result can overcome the ground for refusal or invalidity contained in Article 3(1)(e), second indent, there is nothing in the wording of that provision to allow such a conclusion.

In refusing registration of such signs, Article 3(1)(e), second indent, of the Directive reflects the legitimate aim of not allowing individuals to use registration of a mark in order to acquire or perpetuate exclusive rights relating to technical solutions.

Where the essential functional characteristics of the shape of a product are attributable solely to the technical result, Article 3(1)(e), second indent, precludes registration of a sign consisting of that shape, even if that technical result can be achieved by other shapes. ${ }^{10}$

The ECJ concluded:

In the light of those considerations, the answer to the fourth question must be that Article 3(1)(e), second indent, of the Directive must be interpreted to mean that a sign consisting exclusively of the shape of a product is unregistrable by virtue thereof if it is established that the essential functional features of that shape are attributable only to the technical result. Moreover, the ground for refusal or invalidity of registration imposed by that provision cannot be overcome by establishing that there are other shapes which allow the same technical result to be obtained. ${ }^{11}$

Consequently, under Article 7(1)(e)(ii) CTMR a sign will be excluded from registration when:

1. the sign consists exclusively of the shape of the product, and

2. the shape of the product is necessary to obtain a technical result, or to use the terms used by the ECJ, when the essential functional features of that shape are attributable only to the technical result.

The ECJ's judgment in Philips $v$ Remington prompted trade mark offices in some Member States to change their evaluation of functional shapes. For example, before Philips $v$ Remington, the German Patent and Trade Mark Office allowed trade mark registration for primarily functional product configuration marks, where it was satisfied that alternative shapes could perform the same function. Following the ECJ's judgment in Philips $v$ Remington, however, the German

10 Philips $v$ Remington, paragraphs 81-83, emphasis added.

11 Philips $v$ Remington, paragraph 84, emphasis added.

12 A similar policy underlies the 'substantial value' exclusion in Art 7(1)(e)(iii) CTMR, which excludes from trade mark protection signs which consist exclusively of the shape which gives substantial value to the goods. Here, the balance to be struck is between trade mark and copyright/design protection. The rationale of Art 7(1)(e)(iii) is to avoid
Patent and Trade Mark Office abandoned this approach and, in a decision of 2 February 2005, cancelled the German equivalent of Lego's three-dimensional trade mark.

\section{Policy interests underlying the functionality exclusion and Philips $v$ Remington}

Under Philips $v$ Remington, the rationale of Article 7(1)(e)(ii) CTMR is to disallow the creation of any monopoly in 'shapes whose essential characteristics perform a technical function'. This absolute ground of refusal is intended to prevent a trade mark from being extended beyond its lawful role of origin indicator to an unlawful obstacle preventing competitors from freely offering for sale the same shape that fulfils a technical function.

To avoid the exclusion of Article 7(1)(e)(ii), it is not sufficient for competitors to have access to one shape that fulfils the intended technical function. Competitors must have access to every shape the essential characteristics of which fulfil a technical function; in other words, they must be free to choose whatever shape they want. Therefore, once it is determined that the essential features of the shape are attributable only to a technical result, the existence of other shapes to achieve an identical technical result will not help overcome the functionality exclusion.

A second, related policy interest underlying Article 7(1)(e)(ii) is the desire to safeguard the balance between trade marks and patents. The duration of patent protection is by definition limited in time. It is a basic tenet of patent law that, when a patent is granted, the patentee receives temporary exclusive rights to make the claimed invention. In return, he must provide a complete description of the invention and give to the public sufficient information to allow it to practice the invention. Once the patent expires, the public is free to make use of the invention described in the patent. ${ }^{12}$

The same is not true for trade mark rights, which protect not technical but commercial assets. There is no policy reason to limit the duration of the trade mark protection as long as the trade mark is used by

\footnotetext{
that design and copyright protection for shapes which give substantial value to the goods, having been limited in time, could be bypassed by trade mark law. For a recent application, see the decision of the OHIM First Board of Appeal of 10 September 2008 in Case R 497/2005-1 concerning the Bang \& Olufsen loudspeaker (after the original decision of the First Board was annulled by the CFI).
} 
its owner and remains distinctive for the goods or services claimed.

This balance is upset when a potentially indefinite protection under the trade mark system is awarded to essentially functional or technical shapes. Such shapes should become part of the public domain no later than 20 years after the first patent application was filed, or earlier, if no patent application was filed or if it was allowed to lapse. The functional know-how that should have fallen in the public domain after expiry of the patent could become an exclusive and potentially indefinite monopoly if a trade mark registration is obtained by the former patentee.

In his opinion in Philips $v$ Remington, the AdvocateGeneral clearly stated that the purpose of Article 3(1)(e)(ii) of the Directive is to ensure that the duration of IP protection on patents and designs is limited:

The immediate purpose in barring registration of merely functional shapes or shapes which give substantial value to the goods is to prevent the exclusive and permanent right which a trade mark confers from serving to extend the life of other rights which the legislature has sought to make subject to limited periods. I refer, specifically, to the legislation on industrial patents and designs.

Were it not for the existence of subparagraph (e) of Article 3(1), it would be easy to overturn the balance of public interest which must exist between rewarding innovation fairly, by granting exclusive protection, and encouraging industrial development, which entails placing time-limits on such protection, with the purpose of making the goods or the design freely available once the time-limit expires. ${ }^{13}$

\section{The CFI's functionality analysis}

In a well-reasoned application of the Philips $v$ Remington doctrine, the CFI clarified a number of issues raised by the functionality exclusion and dismissed Lego's often strained interpretation of the ECJ judgment.

\section{Does the shape have to be entirely functional to be excluded from trade mark protection?}

The ECJ held in Philips $v$ Remington that not all of the features of the shape must perform a technical function

13 Advocate-General Ruiz-Jarabo Colomer's Opinion of 23 January 2001 in Philips $v$ Remington, paragraphs 30-31.

14 Advocate-General Ruiz-Jarabo Colomer's opinion of 23 January 2001 in Philips $v$ Remington (paragraph 28).

15 In the context of the relative ground of refusal in Art 8(1)(b) CTMR, see CFI, 13 June 2006, Case T-153/03 Inex SA v OHIM-Robert Wiseman \& Sons Ltd; in the context of distinctiveness under Art 7(1)(b) CTMR, see in order for the exclusion under Article 7(1)(e)(ii) CTMR to apply. When viewed as a whole, only those features that are 'essential' must be functional.

In his opinion in Philips $v$ Remington, the AdvocateGeneral had already stated that the addition of a minor feature that is arbitrary cannot save the shape from the functionality exclusion.

Use of the phrase 'essential features' means that a shape containing an arbitrary element which, from a functional point of view, is minor, such as its colour, does not escape the prohibition. ${ }^{14}$

The approach followed by both the ECJ and the Advocate-General is entirely consistent with the classic principle of trade mark law that the mark under scrutiny must not be 'dissected' but instead must always be analysed as a whole, with particular attention to those features of the mark that are 'dominant' or 'distinctive'. All examinations under trade mark law concern the sign as a whole, whereby some features are given greater weight than others. This is repeatedly confirmed in established CFI case law regarding absolute and relative grounds of refusal. ${ }^{15}$

It follows that words such as 'exclusively' or 'solely' should not be given an over-literal or rigid interpretation. As the Chancery Division (England and Wales) neatly put it in after Philips $v$ Remington: '... I would therefore be wary of interpreting each word of [the ECJ's Philips $v$ Remington judgment] as if it were a piece of sacred text.' ${ }^{16}$

The CFI confirmed that, under the Philips $v$ Remington judgment, the functionality of the shape must be assessed by reference to its essential characteristics only.

It is apparent from [the expression 'essential characteristics which perform a technical function'] that the addition of non-essential characteristics having no technical function does not prevent a shape from being caught by that absolute ground of refusal if all the essential characteristics of that shape perform such a function. Accordingly, the Grand Board of Appeal was right to analyse the functionality of the shape at issue by reference to the characteristics which it considered to be essential. It must therefore be held that it correctly interpreted the term 'exclusively. ${ }^{17}$
CFI 15 March 2006, Case T-129/04 Develey Holding GmbH \& Co Beteiligungs KG v OHIM, and CFI, 17 January 2006, Case T-398/04 Henkel KGaA v OHIM.

16 Koninklijke Philips Electronics v Remington Consumer Products Limited and Rayovac Europe Limited [2004] EWHC 2327 (Ch), (pages 1042-1113, paragraph 34 in fine).

17 Lego v OHIM-MEGA Brands, paragraph 38. 


\section{Who decides what is essential and functional?}

Before the CFI, Lego argued that the essential features of the shape should be determined from the point of view of the consumer. If correct, this would make 'essential' synonymous with 'distinctive'. However, the elements that are distinctive from the consumer's point of view do not necessarily coincide with those that are 'essential' in the context of a functionality analysis. The reason is simple: the average consumer does not always know which technical functions, if any, are performed by the various features of the shape.

The functionality of the essential features of a shape should be determined by assessing the shape as a whole, whereby particular attention should be given to the technical ('man of the art') evidence filed by the parties so as to allow the Court to understand fully the role of each of the features of the shape under examination. If, based on the evidence on file and with particular regard for the technical evidence, the Court finds that the shape is essentially functional, it should refuse registration under Article 7(1)(e)(ii).

The CFI confirmed in Lego v OHIM-MEGA Brands that it should not be left to the consumer to determine what are the essential characteristics of a shape in the context of a functionality analysis.

The perception of the target consumer is not relevant to the analysis of the functionality of the essential characteristics of a shape. The target consumer may not have the technical knowledge necessary to assess the essential characteristics of a shape and therefore certain characteristics may be essential from his point of view even though they are not essential in the context of an analysis of functionality and vice versa. Accordingly, it must be held that the essential characteristics of a shape must be determined objectively for the purposes of applying Article 7(1)(e)(ii) of Regulation No 40/94, on the basis of its graphic representation and any descriptions filed at the time of the application for the trade mark. ${ }^{18}$

\section{What is the relevance of alternative shapes?}

Paragraph 83 of Philips $v$ Remington states unequivocally that Article 7(1)(e)(ii) excludes from trade mark protection those shapes whose essential characteristics are attributable solely to the technical result, even if that technical result can be achieved by other shapes. This is fully consistent with the policy interest underlying Article 7(1)(e)(ii), which is not just to give

\footnotetext{
18 Lego v OHIM-MEGA Brands, paragraph 70, emphasis added.

19 See reference to 'freedom of choice' in paragraph 79 of Philips $v$ Remington.

20 Lego v OHIM-MEGA Brands, paragraph 39, emphasis added.
}

competitors access to a shape that performs the technical function but rather to safeguard their freedom to choose any shape for this purpose. ${ }^{19}$

Therefore, the correct meaning of 'necessary' in this context is that the shape with its essential features suffices to achieve the technical result, in which case trade mark protection is excluded. As soon as that has been established, the fact that the same technical result can also be achieved by other shapes is irrelevant and cannot overcome the functionality exclusion.

This was confirmed by the CFI in Lego $v$ OHIMMEGA Brands.

... it follows from paragraphs 81 and 83 of [Philips $v$ Remington] that the expression 'necessary to obtain a technical result'... does not mean that that absolute ground for refusal applies only if the shape at issue is the only one which could achieve the intended result.... It follows that the Grand Board of Appeal did not err in considering that the term 'necessary' means that the shape is required to obtain a technical result, even if that result can be achieved by other shapes. ${ }^{20}$

In other words, it is not sufficient that $a$ shape is available that performs a technical function. Rather, all shapes that perform such a technical function must, in the absence of patent protection, be free for all to use.

\section{Can a functional shape acquire distinctiveness?}

Under Article 7(3) CTMR, acquired distinctiveness can only save trade marks barred under Article 7(1)(b), (c), and (d) CTMR, but not those barred under (e). This was confirmed by the ECJ in Philips $v$ Remington (paragraph 75$)^{21}$

Under the terms of Articles 7(1)(e)(ii) and 7(3) CTMR, the functionality of a feature is an objective quality, unrelated to any perception or recognition by the consumer of the same feature as being distinctive. In contrast, acquired distinctiveness is a subjective quality that has its rightful place in an analysis of the registrability of not inherently distinctive (Article 7(1)(b)), descriptive (Article 7(1)(c)), and generic (Article 7(1)(d)) marks. Acquired distinctiveness does not enter into the discussion regarding any other absolute bars to registrability, especially functionality (Article 7(3)).

21 The unavailability of the acquired distinctiveness defence under Art 7(3) CTMR for the exclusions under Art 7(1)(e) was emphatically confirmed by the OHIM First Board of Appeal in the above-referenced decision about the Bang \& Olufsen loudspeakers (see footnote 14 paragraphs 18 and 19). 


\section{What is the relevance of disclosure of the shape in expired patents?}

Shapes identical or similar to the Lego brick had been disclosed in numerous expired patents, including the Page patents and Lego's improvement patents. The OHIM Grand Board stressed, and the CFI confirmed, that patent disclosure by itself is not a bar to the shape being registered as a trade mark. However, in the circumstances of this case, these particular expired patents were key facts in the functionality analysis, and the OHIM Grand Board qualified them in concreto as 'practically irrefutable evidence that the features therein disclosed or claimed are functional. ${ }^{22}$

This holding, which is fully consistent with those of courts in other jurisdictions, ${ }^{23}$ is hardly surprising, since patents will necessarily relate to technical or functional features. The fact that a shape is disclosed and claimed in one or more expired patents is therefore strong evidence that the given shape achieves a technical result.

The CFI found that the OHIM Grand Board did not base its finding of functionality on the disclosure of the various features of the shape in prior patents, and that it referred to such disclosure only as corroborating evidence for its finding of functionality. ${ }^{24}$ The question whether evidence of prior disclosure in a patent was irrefutable evidence of the functionality of the shape was therefore deemed irrelevant.

\section{Delicate balance}

The rules regarding the availability of trade mark protection reflect a delicate balance between the protection of the freedom to compete and the protection of immaterial assets, such as goodwill. An object can in principle be the object of different kinds of overlapping IP rights. However, the rationale behind the absolute grounds of refusal in Articles 7 (1)(e)(ii) and (iii) is to ensure that the trade mark regime, which offers exclusive rights of a potentially unlimited duration, is not abused to perpetuate a monopoly on a product shape that formerly was protected by IP rights of a limited duration.

This is the lesson Lego has learned from the CFI judgment of 12 November 2008. Lego's appeal before the ECJ will result in a judgment at par with Philips $v$ Remington in which the Court will have the opportunity to further clarify its doctrine concerning the functionality exclusion.

doi:10.1093/jiplp/jpp069

Advance Access Publication 14 May 2009
22 OHIM Grand Board of Appeal, 10 July 2006, case R 856/2004-G, paragraphs $39-42$.

23 The German Bundesgerichtshof held in Philips $v$ Remington, 17 November 2005, that patent(s) granted for the shape of the product for which a trade mark is claimed are a strong indication that the shape is exclusively dictated by function, even if the patent(s) have in the mean time expired (paragraph 8). The US Supreme Court held in TrafFix that 'a utility patent is strong evidence that the features therein claimed are functional' (Annex 1 to TrafFix Devices, Inc. v Marketing Displays, Inc., 532 US 23 (2001)). The same is true for Canada (Thomas \& Betts, Ltd v Panduit Corp. et al. 4 CPR (4th) 498).

24 Lego v OHIM - MEGA Brands, paragraphs 79, 85, and 86. 